\title{
Response of Gallium Nitride Chemiresistors to Carbon Monoxide is due to Oxygen Contamination
}

\author{
Ravi Mohan Prasad, ${ }^{\mathrm{a}, \mathrm{d}}$ Stefan Lauterbach, ${ }^{\mathrm{a}}$ Hans-Joachim Kleebe, ${ }^{\mathrm{a}}$ Odile Merdrignac-Conanec, ${ }^{\mathrm{c}}$ Nico- \\ lae Barsan, ${ }^{\mathrm{b}}$ Udo Weimar, ${ }^{\mathrm{b}}$ and Aleksander Gurlo ${ }^{* a, \mathrm{e}}$ \\ a - Technische Universität Darmstadt, Fachbereich Material-und Geowissenschaften, Fachgebiet Disperse Feststoffe, \\ Alarich-Weiss-Straße 2, 64287 Darmstadt, Germany \\ b - Tübingen University, Faculty of Science, Chemistry Department, Auf der Morgenstelle 15, 72076 Tübingen, Germany. \\ c - UMR CNRS 6226, Institut des Sciences Chimiques de Rennes, Equipe Verres et Céramiques, Université de Rennes 1, \\ 35042 Rennes Cedex, France \\ d - now at Indian Institute of Technology Ropar, School of Mechanical, Materials and Energy Engineering, Nangal Road, \\ Rupnagar 140001, Punjab, India \\ e - now at Fachgebiet Keramische Werkstoffe / Chair of Advanced Ceramic Materials, Institut für Werkstoffwissenschaften \\ und -technologien, Technische Universitaet Berlin, Hardenbergstraße 40, 10623 Berlin, Germany
}

Supporting Information Placeholder

\begin{abstract}
We report on the influence of oxygen impurities on the gas sensing properties of gallium nitride $(\mathrm{GaN})$ chemiresistors. As shown by XRD, elemental analysis and TEM characterization, surface oxidation of $\mathrm{GaN}$ - for example, upon contact to ambient air atmosphere - creates an oxidative amorphous layer which provides the sites for the sensing towards $\mathrm{CO}$. Treating this powder under dry ammonia at $800{ }^{\circ} \mathrm{C}$ converts the oxide layer in nitride and consequently the sensing performance towards $\mathrm{CO}$ is dramatically reduced for ammonia treated $\mathrm{GaN}$ gas sensors. Hence the response of $\mathrm{GaN}$ sensors to $\mathrm{CO}$ is caused by oxygen in the form of amorphous surface oxide or oxynitride.
\end{abstract}

Keywords: chemiresistors, gallium nitride, carbon monoxide, oxygen, gallium oxide

Nowadays gas sensors based on metal oxides $\left(\mathrm{SnO}_{2}\right.$, $\mathrm{ZnO}, \mathrm{TiO}_{2}, \mathrm{WO}_{3}, \mathrm{In}_{2} \mathrm{O}_{3}$, etc.) are widely used for the detection of toxic and combustible gases as well as for air quality control in buildings, vehicles and airplanes. ${ }^{1-4}$ Metal nitride (e.g. GaN) sensors are known to be capable of operation in harsh environmental conditions. ${ }^{5-8}$ With a wide bandgap of $3.45 \mathrm{eV}$ and strong chemical bonds, GaN combines favorable properties especially for high power, high-frequency, and high-temperature devices. GaN powders and films have been applied for sensing $\mathrm{H}_{2}, \mathrm{CO}$ and $\mathrm{CH}_{4} \cdot{ }^{6-10}$ Oxygen is a common impurity in $\mathrm{GaN}$ that influences significantly electrical and optical properties of GaN-based materials (see ref. ${ }^{11}$ and references therein). Besides substitutional oxygen ${ }^{12}$, which can occur under typical synthesis conditions, i.e. heat treatment under ammonia or CVD process, an oxide passivation on the surface of freshly produced GaN develops over time. GaN surfaces are becoming firstly covered with amorphous $\mathrm{GaO}_{\mathrm{x}}$ layer that finally crystallizes to polycrystalline $\mathrm{Ga}_{2} \mathrm{O}_{3}$ film. ${ }^{13}$ Passivation oxide layer on GaN surfaces is a well known effect studied in much detail in previous works. ${ }^{11}$ However, the effect of surface oxygen impurities as well as surface oxide layer on the gas sensing properties of GaN remains still unclear, even if there are some indications of that. $^{10,14}$

In the present work, we study the influence of oxygen impurities in $\mathrm{GaN}$ sensors applied for $\mathrm{CO}$ detection in the oxygen-free atmosphere. GaN specimens were prepared from as-synthesized oxygen-contaminated $\mathrm{GaN}$ powder and post-treated under dry nitrogen and dry ammonia gases as well. The latter is known to be an effective method for the removal of oxygen from $\mathrm{GaN}$ surfaces. ${ }^{15}$

Table 1 displays the results of elemental analysis and phase composition of untreated ("GaN"), nitrogen ("GaN/ $\mathrm{N}_{2}$ ") and ammonia ("GaN/ $\mathrm{NH}_{3}$ ") treated $\mathrm{GaN}$ powders.

Table 1. Elemental analysis and phase composition of as-received (untreated) GaN powders and heat-treated specimens in $\mathrm{N}_{2}$ and $\mathrm{NH}_{3}$ gases.

\begin{tabular}{|c|c|c|c|c|c|c|}
\hline \multirow[t]{2}{*}{ Specimen } & \multirow{2}{*}{$\begin{array}{l}\text { Synthesis/ } \\
\text { treatment } \\
\text { conditions }\end{array}$} & \multirow{2}{*}{$\underset{\text { (wt.\%) }}{\mathrm{N}}$} & \multirow{2}{*}{$\begin{array}{c}\mathbf{O} \\
\text { (wt.\%) }\end{array}$} & \multirow{2}{*}{$\begin{array}{c}\mathrm{nO} / \\
(\mathrm{nO}+\mathrm{nN}) \\
\%\end{array}$} & \multicolumn{2}{|c|}{ Phase composition } \\
\hline & & & & & (XRD) & (TEM) \\
\hline "GaN" & $\begin{array}{l}\beta-\mathrm{Ga}_{2} \mathrm{O}_{3} \text { treated } \\
\text { in } \mathrm{NH}_{3}(900 \\
{ }^{\circ} \mathrm{C}, 24 \mathrm{~h} \text { ) and } \\
\text { kept in ambient } \\
\text { air for about six } \\
\text { months }\end{array}$ & 14.9 & 2.8 & 14 & $\mathrm{GaN}$ & $\begin{array}{l}\mathrm{GaN}+ \\
\mathrm{Ga}_{2} \mathrm{O}_{3}+ \\
\text { amorphous } \\
\text { surface }\end{array}$ \\
\hline "GaN/N ${ }_{2}$, "[a] & $\begin{array}{l}\text { "GaN" treated } \\
\text { in } \mathrm{N}_{2}\left(600{ }^{\circ} \mathrm{C} \text {, }\right. \\
2 \mathrm{~h})\end{array}$ & 15.0 & 2.7 & 13 & $\mathrm{GaN}$ & not studied \\
\hline$" \mathrm{GaN} / \mathrm{NH}_{3} "$ & $\begin{array}{l}\text { "GaN" treated } \\
\text { in } \mathrm{NH}_{3}(800 \\
\left.{ }^{\circ} \mathrm{C}, 6 \mathrm{~h}\right)\end{array}$ & 15.9 & 1.6 & 8 & $\mathrm{GaN}$ & $\begin{array}{l}\mathrm{GaN}+ \\
\mathrm{Ga}_{2} \mathrm{O}_{3}{ }^{[b]}+ \\
\text { amorphous } \\
\text { surface }\end{array}$ \\
\hline
\end{tabular}

[a] "GaN" specimen treated under conditions $\left(\mathrm{N}_{2}\right)$ applied for the firing of the sensors (for details, see experimental methods in SI); [b] smaller $\mathrm{Ga}_{2} \mathrm{O}_{3}$ particles if compared to untreated " $\mathrm{GaN}$ ".

Let us note that the oxygen content of the "GaN/ $\mathrm{N}_{2}$ " specimen remains similar to that of "GaN" sample, indicating that, as intended for, the treatment in dry nitrogen, in the conditions applied for the sensors preparation does not modify the chemical composition of the sensors. However, a significant difference in oxygen content is observed in the "GaN" and "GaN/ $\mathrm{NH}_{3}$ " specimens. $\mathrm{GaN}$ specimen synthesized from $\beta-\mathrm{Ga}_{2} \mathrm{O}_{3}$ under ammonia at $900{ }^{\circ} \mathrm{C}$ and stored in air for about six months possesses about $2.8 \mathrm{wt} . \%$ of oxygen, which is reduced to about 1.6 wt. $\%$ after treatment in ammonia at $800{ }^{\circ} \mathrm{C}$ for 6 hours.

No difference in the $\mathrm{X}$-ray diffraction patterns is observed for the "GaN", "GaN/ $\mathrm{N}_{2}$ ", and "GaN/ $\mathrm{NH}_{3}$ " powders (Figure 1) as well as for GaN sensors before and 
after sensing tests under $\mathrm{CO}\left(20-120 \mathrm{ppm}\right.$ in $\left.\mathrm{N}_{2}\right)$ at $530{ }^{\circ} \mathrm{C}$ (Figure 2).

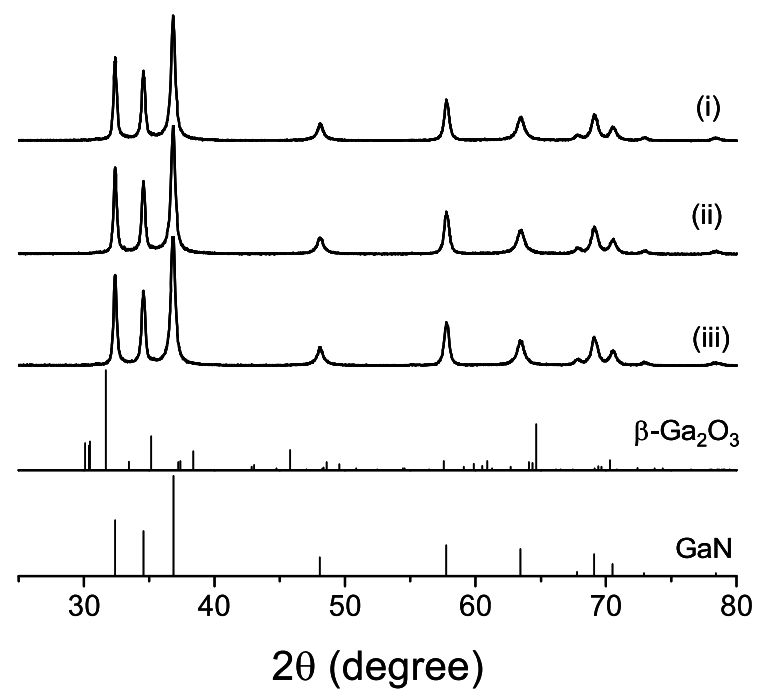

Figure 1. X-ray powder diffraction (XRPD) patterns of "GaN" (i), "GaN/ $\mathrm{N}_{2}$ " (ii), and "GaN/NH $\mathrm{NH}_{3}$ " (iii) specimens (see Table 1). The diffraction patterns of $\beta-\mathrm{Ga}_{2} \mathrm{O}_{3}$ (ICDD PDF No. 43-1012, monoclinic, space group $\mathrm{C} 2 / \mathrm{m}, \mathrm{a}=12.23 \AA, \mathrm{b}=3.04 \AA, \mathrm{c}=5.80$ $\AA$ ) and GaN (ICDD PDF No. 50-0792, hexagonal, space group $\mathrm{P}_{3} m c, \mathrm{a}=3.18907 \AA, \mathrm{b}=3.18907 \AA, \mathrm{c}=5.1855 \AA$ ) are shown at the bottom.

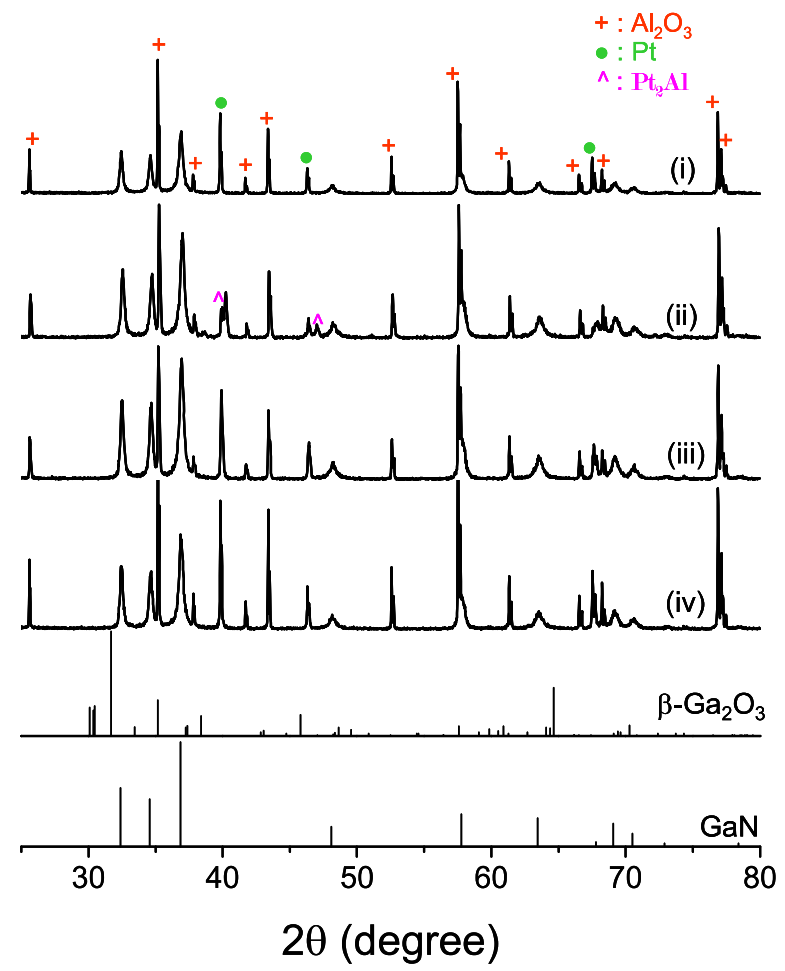

Figure 2. X-ray powder diffraction (XRPD) patterns of $\mathrm{GaN}$ layers on sensor substrates before and after gas sensing measurements: (i) and (ii) represent "GaN" coated sensor substrates before and after sensing measurement, respectively; (iii) and (iv) represent " $\mathrm{GaN} / \mathrm{NH}_{3}$ " coated sensor substrates before and after sensing measurement. Here, it should be noted that XRD characterization done on the GaN coated sensor substrates before sensing measurement, specimen (i) and (iii), are different sensor samples than those after sensing measurements, specimen (ii) and (iv). $\mathrm{Al}_{2} \mathrm{O}_{3}$ and $\mathrm{Pt}$ reflections are due to sensor substrate and electrodes.

Figure 3 shows the TEM images of "GaN" and "GaN/ $\mathrm{NH}_{3}$ " specimens. For both "GaN" and "GaN/ $\mathrm{NH}_{3}$ " powders an amorphous surface layer is observed. Surface $\mathrm{Ga}_{2} \mathrm{O}_{3}$ particles are seen for "GaN" powder (Figure 3A,B), as well as for " $\mathrm{GaN} / \mathrm{NH}_{3}$ " powder (Figure $3 \mathrm{C}, \mathrm{D}, \mathrm{E}$ ). However, larger particles were observed via TEM in the untreated powders compared to the ammonia treated sample, where the particles are in the order of $2-5 \mathrm{~nm}$.

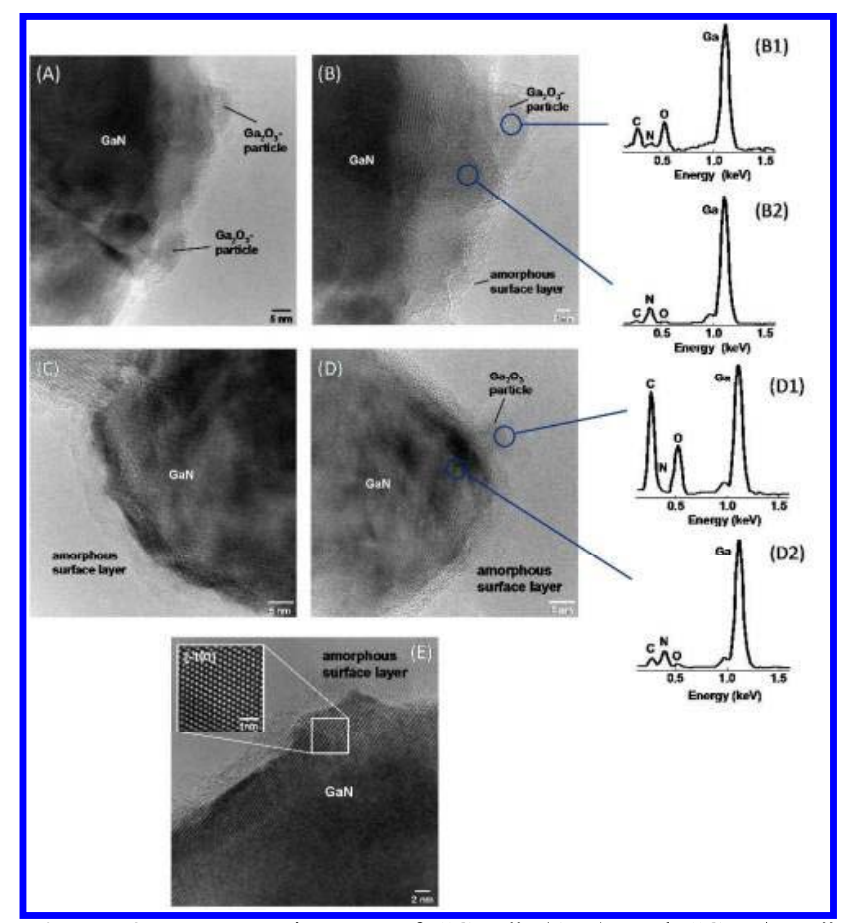

Figure 3. HRTEM images of "GaN" $(\mathrm{A}, \mathrm{B})$ and "GaN/NH," $(\mathrm{C}, \mathrm{D}, \mathrm{E})$; inset in (E) FFT filtered image of the matrix near to the surface of "GaN/NH," specimen. Corresponding EDS spectra are shown in (B1, B2, D1, D2).

EDS chemical analysis reveals that the particles on the surface in both samples are $\mathrm{Ga}_{2} \mathrm{O}_{3}$ which are not present in the XRD diffraction pattern (Figure 1), whereas the matrix in the close vicinity of the particles is GaN (see FFT filtered inset in Figure 3E). The amorphous surface layer shows peaks in EDS which can be assigned to gallium and oxygen. Because the surface layer also contributes to the analysis done at the bulk sample, the EDS will also show a minor amount of oxygen. The carbon peaks are due to contamination during the measurement and are more pronounced for the small particles. Our finding is similar to the mechanism of $\mathrm{GaN}$ surface oxidation as proposed in other works ${ }^{13,16,17}$, which show the formation of a $\mathrm{Ga}_{2} \mathrm{O}_{3}$ layer covering $\mathrm{GaN}$ particles.

To assess the performance of "GaN" and "GaN/NH 3 " sensors in oxygen free-conditions, gas sensing properties of the sensors were studied at $350^{\circ} \mathrm{C}$ and $530{ }^{\circ} \mathrm{C}$ towards different CO (10-120 ppm) concentrations (Figure 4A,B). A number of significant differences are observed between "GaN" and "GaN/NH 3 " sensors. Upon CO exposure, reasonable resistance changes are measured for the "GaN" sensor with rather fast response and recovery times at both 
temperatures, whereas for the " $\mathrm{GaN} / \mathrm{NH}_{3}$ " coated sensor only a weak response is observed at $530^{\circ} \mathrm{C}$. This effect was reproducible and was observed repeatedly on several sensors. Sensor signal towards $\mathrm{CO}$ is dramatically increased when oxygen in $\mathrm{GaN}$ is present (Figure $4 \mathrm{C}$ ). Sensor signal for "GaN/ $\mathrm{NH}_{3}$ " sensors were 3-10.4 times (at $350{ }^{\circ} \mathrm{C}$ ) and 1.3-3.1 times (at $530{ }^{\circ} \mathrm{C}$ ) weaker than "GaN" sensors in the CO (20-120 ppm).
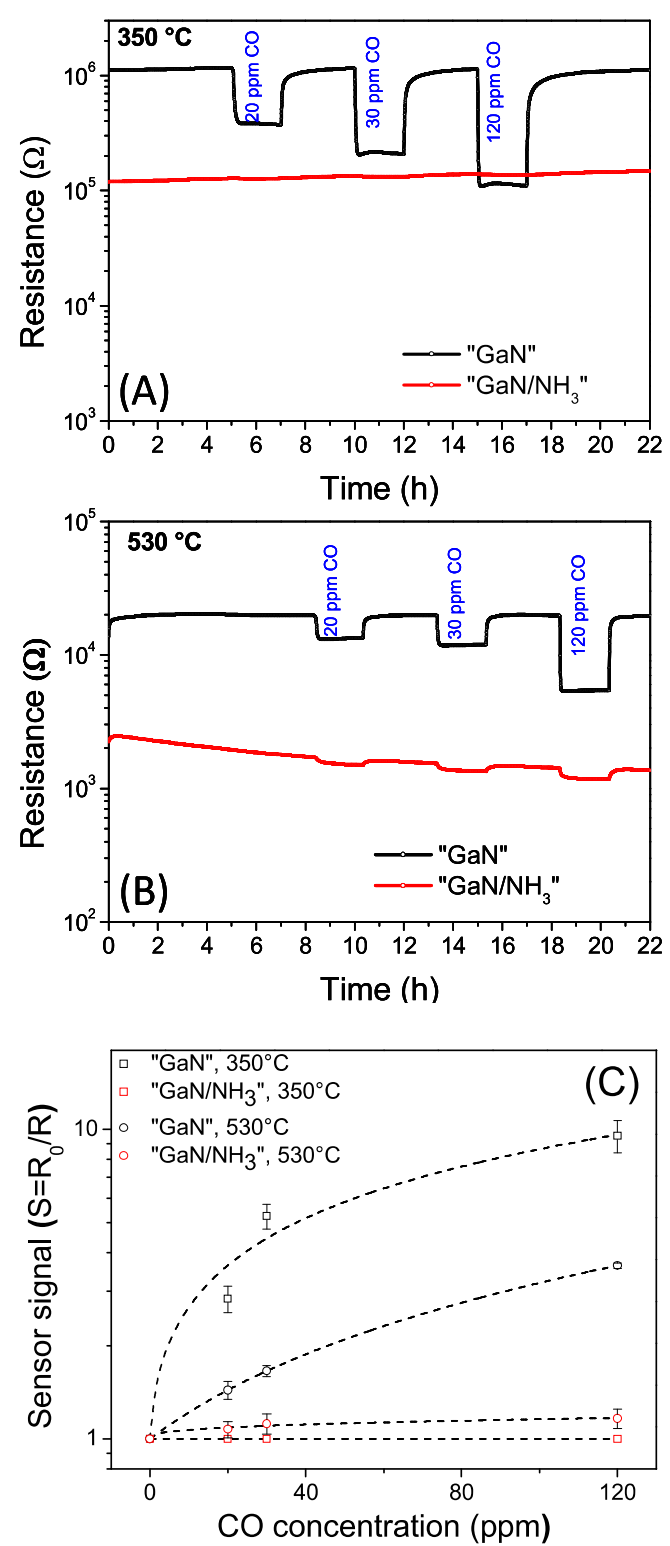

Figure 4. Transient response $(A, B)$ and sensor signals $\left(S=R_{0} / R\right)$ (C) of " $\mathrm{GaN}$ " and " $\mathrm{GaN} / \mathrm{NH}_{3}$ " sensors during exposure to $\mathrm{CO}(20$, 30 and $120 \mathrm{ppm}$ ) in nitrogen at $350{ }^{\circ} \mathrm{C}$ and $530{ }^{\circ} \mathrm{C} ; \mathrm{R}_{0}$ is baseline resistance whereas $\mathrm{R}$ is the resistance under different $\mathrm{CO}$ concentrations. In (c) the experimental points averaged over three measurements are fitted with a function $\mathrm{S}=1+\mathrm{aC}^{\mathrm{b}}$ where $\mathrm{a}=0.36,0.03$, 0.02 and $b=0.66,0.36,1.00$ for " $\mathrm{GaN}$ " sensors at 350 and 530 ${ }^{\circ} \mathrm{C}$, and " $\mathrm{GaN} / \mathrm{NH}_{3}$ " sensors at $350{ }^{\circ} \mathrm{C}$, respectively.

As shown recently ${ }^{18}$, the stoichiometric GaN undergoes surface amorphisation, the amorphous phase (a-GaN(O) afterwards) is stabilized herewith by the oxygen incorporation. Oxygen resides in dislocations and grain boundaries rather than substitutes for nitrogen in the bulk. Interestingly, we observe an amorphous surface in both, i.e. "GaN" and "GaN/ $\mathrm{NH}_{3}$ " that show quite remarkable difference in the gas sensing properties. The main difference we found is the oxygen content, i.e. ca. $14 \%$ in "GaN" and ca. $8 \%$ in "GaN/ $\mathrm{NH}_{3}$ " specimens and a decrease in the amount and size of $\mathrm{Ga}_{2} \mathrm{O}_{3}$ particles. Therefore, we conclude that the difference in the gas sensing properties of " $\mathrm{GaN}$ " and " $\mathrm{GaN} / \mathrm{NH}_{3}$ " is caused by the local structural arrangements that involve $\mathrm{Ga}-\mathrm{N}$ and $\mathrm{Ga}-\mathrm{O}$ bonds. $\mathrm{GaN}$ consists of slightly distorted $\left[\mathrm{GaN}_{4}\right]$ tetrahedral units with the hybridized $\mathrm{sp}^{3}$ orbitals that form in-plane and out-of-plane bonds (Figure 5A). The X-ray Absorbance Spectroscopy (XAS) results indicate that the $\left[\mathrm{GaN}_{4}\right]$ tetrahedra are modified in the amorphous films due to the preferential substitution of the out-of-plane components, as a result oxygen-substituted polyhedra appear at the GaN surface. ${ }^{19,20}$ As shown by $\mathrm{Ga} \mathrm{L}_{3^{-}}, \mathrm{N} \mathrm{K}$ and $\mathrm{O} \mathrm{K}$-edge XAS, the coordination symmetry of gallium in a-GaN(O) depends on the amount of oxygen incorporated, i.e. with increasing oxygen amount the tetrahedral $\left[\mathrm{Ga}(\mathrm{N}, \mathrm{O})_{4}\right]$ units are transformed into distorted octahedral $\left[\mathrm{Ga}(\mathrm{N}, \mathrm{O})_{6}\right]$ units that are characteristic for gallium oxynitride. A full substitution of $\mathrm{N}$ by $\mathrm{O}$ subsequently forms $\beta-\mathrm{Ga}_{2} \mathrm{O}_{3}$ (Figure $5 \mathrm{~A}$ ). Effectively, both $\left[\mathrm{Ga}(\mathrm{N}, \mathrm{O})_{4}\right]$ and $\left[\mathrm{Ga}(\mathrm{N}, \mathrm{O})_{6}\right]$ units look amorphous in XRD characterization (Figure 1). Figure 5B displays a model of transformation stages of $\mathrm{GaN}$ specimens studied in the present work. The decrease in the oxygen content in $\mathrm{GaN}$ powder from ca. 14 to $8 \%$ after its treatment under ammonia at $800{ }^{\circ} \mathrm{C}$ is indicated by the decrease in the amount and size of $\mathrm{Ga}_{2} \mathrm{O}_{3}$ particles and by the decrease of thickness of the surface amorphous gallium oxynitride layer.

Based on results of XRD, elemental analysis and TEM characterization of $\mathrm{GaN}$ powders we can propose that when as-synthesized GaN powder is stored under ambient air condition, surface oxidation of GaN creates an oxidative amorphous layer (that does not appear in the XRD pattern) which provides the sites for the sensing towards CO. Treating this powder under dry ammonia at $800{ }^{\circ} \mathrm{C}$ destroys the oxidative layer (converting to nitride layer) and consequently the sensing performance towards $\mathrm{CO}$ is dramatically reduced for ammonia treated $\mathrm{GaN}$ gas sensors.

Therefore, it is logically coherent to suggest that distorted octahedral $\left[\mathrm{Ga}(\mathrm{N}, \mathrm{O})_{6}\right]$ and $\left[\mathrm{GaO}_{6}\right]$ units in untreated a-GaN(O) with higher oxygen content and $\beta$ $\mathrm{Ga}_{2} \mathrm{O}_{3}$, respectively, provide sensitivity to $\mathrm{CO}$, and tetrahedral $\left[\mathrm{Ga}(\mathrm{N}, \mathrm{O})_{4}\right]$ with lower oxygen content in ammonia treated $\mathrm{GaN}$ do not. Our assumption is confirmed by the similar response to $\mathrm{CO}$ of $\beta-\mathrm{Ga}_{2} \mathrm{O}_{3}$ and untreated$\mathrm{GaN}$ [please refer to supporting information (SI)] that indicates a similar detection mechanism for both, i.e. a chemisorption path that leads to an accumulation layer due to $\mathrm{CO}^{+}$-adsorbates on $\left[\mathrm{Ga}(\mathrm{N}, \mathrm{O})_{6}\right] /\left[\mathrm{GaO}_{6}\right]$ surface that donate electrons to the conduction band of $\mathrm{GaN}$ increasing in this a conductivity of the material. ${ }^{21}$ The effect we observe resembles a significant increase in $\mathrm{CO}$ sensitivity on surface-nitridated $\mathrm{Ga}_{2} \mathrm{O}_{3}$ nanowires ${ }^{22}$ thus indicating an 
activity of mixed-bond $\left[\mathrm{Ga}(\mathrm{N}, \mathrm{O})_{6}\right]$ units in $\mathrm{CO}$ detection both on partially oxidized $\mathrm{GaN}$ or partially nitridated $\mathrm{Ga}_{2} \mathrm{O}_{3}$ materials.

(A)

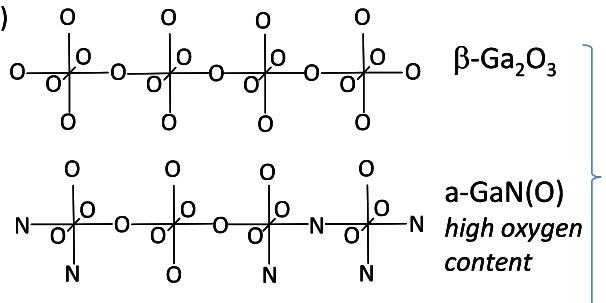<smiles>N=C(O)NNC(O)(O)N=NC(N)(O)O[Na]</smiles>
content

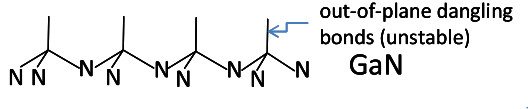

(B)

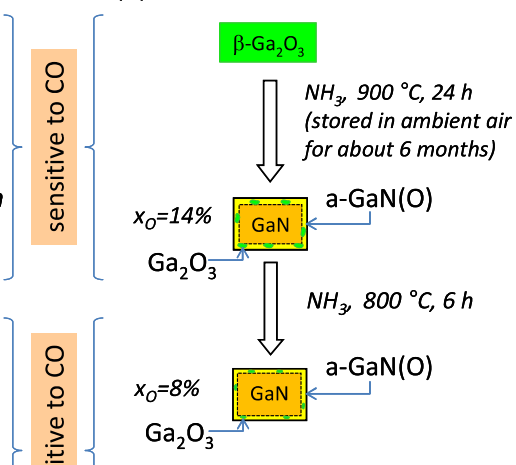

Figure 5. (A) Schematic representation of the local structure model representing the relationship between interaction of oxygen with GaN sensors and their sensitivity to CO. The tetrahedral coordination of Ga remains intact when a low amount of oxygen is incorporated. Interaction of oxygen with out-of-plane dangling bonds lead to the formation of amorphous gallium oxynitride with tetrahedral a$\mathrm{GaN}(\mathrm{O}): \mathrm{GaN}_{3} \mathrm{O}$ units that eliminate out-of-plane Ga-N bonds but do not influence the GaN bulk structure. Further increase of the oxygen amount leads to the formation of a distorted amorphous gallium oxynitride with octahedral a- $\mathrm{GaN}(\mathrm{O}): \mathrm{GaN} \mathrm{O}_{2}$ units. Complete substitution of $\mathrm{N}$ by $\mathrm{O}$ yields in distorted octahedral $\mathrm{GaO}_{6}$ units. (B) Schematic representation of different stages of transformation process, from ammonolysis of $\mathrm{Ga}_{2} \mathrm{O}_{3}$ to $\mathrm{GaN}$ followed by surface oxidation of as-synthesized $\mathrm{GaN}$ under air after storing for 6 months and finally retreatment of "GaN" under ammonia at $800{ }^{\circ} \mathrm{C}$ for $6 \mathrm{~h}$; a-GaN(O) represents amorphous gallium oxynitride layer formed due to surface oxidation.

In summary, the effect of ammonia treatment of assynthesized $\mathrm{GaN}$ based sensors on their gas sensing properties has been investigated. Untreated GaN sensors show high response towards $\mathrm{CO}$ in oxygen-free conditions whereas for ammonia treated $\mathrm{GaN}$ based gas sensors the sensitivity towards $\mathrm{CO}$ is lost at $350{ }^{\circ} \mathrm{C}$ and significantly reduced at $530{ }^{\circ} \mathrm{C}$. This study gives the direct evidence of the oxygen implication in the $\mathrm{CO}$ detection process in oxygen-free conditions of $\mathrm{GaN}$ gas senors. It also points out that for non-oxides based gas sensors, prone to oxidation when exposed to air, accurate characterization of the surface chemistry is of crucial importance..

\section{ASSOCIATED CONTENT}

\section{Supporting Information}

The Supporting Information is available free of charge on the ACS Publications website at DOI...: GaN synthesis, sensor fabrication, characterization methods, gas sensing performance of $\mathrm{Ga}_{2} \mathrm{O}_{3}$ based sensors.

\section{AUTHOR INFORMATION}

\section{Corresponding Author}

*E-mail: gurlo@ceramics.tu-berlin.de

\section{ACKNOWLEDGMENT}

The financial support by the priority program "Adapting surfaces for high temperature applications" (SPP 1299, Grant $\mathrm{Gu}$ 992/3-2) of the German Research Foundation (DFG) is greatly acknowledged. The authors appreciate Michael Huebner for the sensing tests.

\section{REFERENCES}

1. Barsan, N.; Koziej, D.; Weimar, U., Metal oxide-based gas sensor research: How to? Sensor Actuat B-Chem 2007, 121, (1), 18-35.

2. Gurlo, A., Nanosensors: towards morphological control of gas sensing activity. $\mathrm{SnO}_{2}, \mathrm{In}_{2} \mathrm{O}_{3}, \mathrm{ZnO}$ and $\mathrm{WO}_{3}$ case studies. Nanoscale 2011, 3, (1), 154-165.

3. Rock, F.; Barsan, N.; Weimar, U., Electronic nose: Current status and future trends. Chem Rev 2008, 108, (2), 705725 .

4. Tricoli, A.; Righettoni, M.; Teleki, A., Semiconductor Gas Sensors: Dry Synthesis and Application. Angew Chem Int Edit 2010, 49, (42), 7632-7659.

5. Drygas, M.; Olejniczak, Z.; Grzanka, E.; Bucko, M. M.; Paine, R. T.; Janik, J. F., Probing the Structural/Electronic Diversity and Thermal Stability of Various Nanocrystalline Powders of Gallium Nitride GaN. Chem Mater 2008, 20, (21), 6816-6828. 
6. Lee, D. S.; Lee, J. H.; Lee, Y. H.; Lee, D. D., GaN thin films as gas sensors. Sensor Actuat B-Chem 2003, 89, (3), 305310.

7. Kerlau, M.; Merdrignac-Conanec, O.; Reichel, P.; Barsan, N.; Weimar, U., Preparation and characterization of gallium (oxy)nitride powders - Preliminary investigation as new gas sensor materials. Sensor Actuat B-Chem 2006, 115, (1), 4-11.

8. Yun, F.; Chevtchenko, S.; Moon, Y. T.; Morkoc, H.; Fawcett, T. J.; Wolan, J. T., GaN resistive hydrogen gas sensors. Appl Phys Lett 2005, 87, (7).

9. Schalwig, J.; Muller, G.; Eickhoff, M.; Ambacher, O.; Stutzmann, M., Group III-nitride-based gas sensors for combustion monitoring. Mat Sci Eng B-Solid 2002, 93, (1-3), 207214.

10. Patsha, A.; Sahoo, P.; Arnirthapandian, S.; Prasad, A. K.; Das, A.; Tyagi, A. K.; Cotta, M. A.; Dhara, S., Localized Charge Transfer Process and Surface Band Bending in Methane Sensing by GaN Nanowires. J Phys Chem C 2015, 119, (36), 21251-21260.

11. Pearton, S. J.; Zolper, J. C.; Shul, R. J.; Ren, F., GaN: Processing, defects, and devices. J Appl Phys 1999, 86, (1), 1-78.

12. Slack, G. A.; Schowalter, L. J.; Morelli, D.; Freitas, J. A., Some effects of oxygen impurities on AlN and GaN. $J$ Cryst Growth 2002, 246, (3-4), 287-298.

13. Yamada, T.; Ito, J.; Asahara, R.; Watanabe, K.; Nozaki, M.; Nakazawa, S.; Anda, Y.; Ishida, M.; Ueda, T.; Yoshigoe, A.; Hosoi, T.; Shimura, T.; Watanabe, H., Comprehensive study on initial thermal oxidation of $\mathrm{GaN}(0001)$ surface and subsequent oxide growth in dry oxygen ambient. J Appl Phys 2017, 121, (3).

14. Weidemann, O.; Hermann, M.; Steinhoff, G.; Wingbrant, H.; Spetz, A. L.; Stutzmann, M.; Eickhoff, M., Influence of surface oxides on hydrogen-sensitive Pd : GaN Schottky diodes. Appl Phys Lett 2003, 83, (4), 773-775.
15. Grabow, L. C.; UhIrich, J. J.; Kuech, T. F.; Mavrikakis, M., Effectiveness of in situ $\mathrm{NH}_{3}$ annealing treatments for the removal of oxygen from GaN surfaces. Surf Sci 2009, 603, (2), 387-399.

16. Brendt, J.; Samuelis, D.; Weirich, T. E.; Martin, M., An in situ XAS investigation of the kinetics of the ammonolysis of $\mathrm{Ga}_{2} \mathrm{O}_{3}$ and the oxidation of GaN. Phys Chem Chem Phys 2009, 11, (17), 3127-3137.

17. Martin, M.; Dronskowski, R.; Janek, J.; Becker, K. D.; Roehrens, D.; Brendt, J.; Lumey, M. W.; Nagarajan, L.; Valov, I.; Borger, A., Thermodynamics, structure and kinetics in the system Ga-O-N. Prog Solid State Ch 2009, 37, (2-3), 132-152.

18. Budde, F.; Ruck, B. J.; Koo, A.; Granville, S.; Trodahl, H. J.; Bittar, A.; Williams, G. V. M.; Ariza, M. J.; Bonnet, B.; Jones, D. J.; Metson, J. B.; Rubanov, S.; Munroe, P., Stabilization of amorphous GaN by oxygen. $J$ Appl Phys 2005, 98, (6), 063514. 19. Tran, N. H.; Houschuh, W. J.; Lamb, R. N.; Lai, L. J.; Yang, Y. W., Structural order in oxygenated gallium nitride films. J Phys Chem B 2003, 107, (35), 9256-9260.

20. Tran, N. H.; Lamb, R. N.; Lai, L. J.; Yang, Y. W., Influence of oxygen on the crystalline - amorphous transition in gallium nitride films. $J$ Phys Chem B 2005, 109, (39), 1834818351.

21. Gurlo, A.; Riedel, R., In situ and operando spectroscopy for assessing mechanisms of gas sensing. Angew Chem Int Edit 2007, 46, (21), 3826-3848.

22. Park, S. H.; Kim, S. H.; Park, S. Y.; Lee, C., Synthesis and $\mathrm{CO}$ gas sensing properties of surface-nitridated $\mathrm{Ga}_{2} \mathrm{O}_{3}$ nanowires. Rsc Adv 2014, 4, (108), 63402-63407. 
SYNOPSIS TOC

(A)
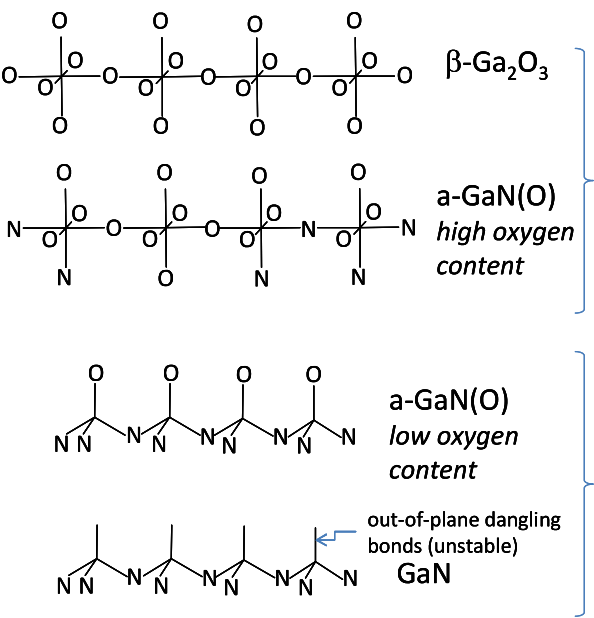

(B)

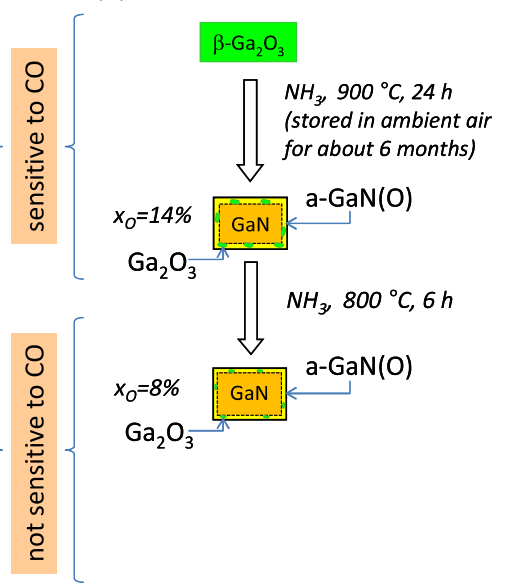

